\title{
Studies on the Consecutive Survey of Succedaneous and Permanent Dentition in the Japanese Children
}

\section{Part 2. Chronological Observations of the Alveolar Bone Patterns at the Period of Successional Replacement}

\author{
by \\ Shoichi ANDO*, Kiwamu SHINBO*, Yoshio SANKA*, \\ Kiyoshi KIYOKAWA*, Takakazu NAKASHIMA*, \\ Shoichi OSHIMA* and Koichi AIZAWA*
}

1. Introduction

2. Method and Materials

3. Results

3.1 Alveolar bone patterns at the normal successional replacement

3.2 Alveolar bone patterns at the abnormal successional replacement

3.3 Behaviors of alveolar bone due to an early loss of deciduous teeth

3.4 Alveolar bone patterns at the successional replacement in the lower anterior region

3.5 Alveolar bone patterns where permanent teeth erupt after twisting or inclining in the bone

3.6 Alveolar bone trabeculation before and after the eruption of permanent teeth

4. Summarization and Considerations

5. Conclusions

\section{Introduction}

The alveolar bone is one of the most important structures involved in support of the teeth and it consists of bundle bone that forms the inner wall of the alveolus in contact with the periodontium and of lamellated bone which lies outside of bundle bone. On the roentgenograph, the former is referred to as linia alba or lamina dura.

These are very important radiographic appearances as diagnostic manifestations in clinical field of dentistry. For this reason, exact interpreting of various patterns of the alveolar bone is of much value not only to the diagnosis of teeth which have com-

* 安藤 正一, 真保 極, 三䇢善雄, 清川 清, 中品 孝和, 大島 章一, 相沢 幸一：Department of

Radiology, Nihon Univ. School of Dentistry (Director: Prof. Shoichi Ando)

Part of the present study was read before the following academic meetings:

The 1st. General Congress of Japan Dental Radiological Society, Oct., 1960.

The 13th. General Meeting of Nihon University Dental Society, Apr., 1961.

The 2naे. General Congress of Japan Dental Radiological Society, Oct., 1961.

The 15th. General Meeting of Nihon University Dental Society, May, 1963.

The 4th. General Congress of Japan Dental Radiological Society, Oct., 1963. 
pleted their eruption, but also to enable us to interpret better the findings observable in the replacement from deciduous to permanent dentition.

AKIYOSHi [1,2] published his research result that "Whether bundle bone or lamellated bone will be produced in the alveolar wall is largely influenced by intensity of functional stimuli exerted on the alveolar wall through the roots." What is meant by this is that bundle bone will be produced in such a spot where the alveolar wall is strongly pulled by occlusal pressure or pressure is intermittently exerted on it, whereas lamellated bone will be produced otherwise.

According to FUJITA [3], the running direction of trabeculae in cancellous sponginosa is concerned with the architectural peculiarity of bones and for observational purposes, he thinks section preparation to be more advantageous over histologic specimens and the former in turn is surpassed by radiographic patterns.

It is to be well accepted that radiographic appearances of these bone structures may give rise to various and complicated patterns at the time of loss of deciduous teeth, permanent eruption and, in particular, pathologic successional replacement. It is within the bounds of reasonable assumption that when some pathologic conditions exist in the periapical region of deciduous teeth, different patterns will be observed as compared with the normal situation.

From these considerations, the present study is concerned with investigations of successional replacemental processes, carried out chronologically over a number of years, with reference to different patterns of the alveolar bone, so that the result would be used with benefit for clinical purposes which will surely help to establish sound treatment planning in dealing with the deciduous precursors.

The published literature is scanty which relates to a radiological investigation extending over years of the alveolar bone patterns in the period of successional replacement of teeth. The reasen is not far to seek, because there is established the standardized radiographic technic which has repeated each time under the precisely identical conditions.

The authers have invented a new devise on the isometric technic for intraoral radiographic method [4], by means of which radiography was taken every three months of the lower premolar region of children in the successional replacemental period. These radiographs give evidence of the various alveolar bone patterns and other changes taking place at the stadium of successional replacement, making it possible for us compare radiographic patterns of pre-eruption with those post-eruption.

For other regions then the lower premolars, the same children were subjected to an annual dental examination as well as the chronological radiography and were studied at full length.

By these chronological investigations, the authors could obtain definite variations of the alveolar bone patterns in the same subjects at the stadium of successional replacement.

\section{Method and Materials}

The subjects under investigation were 289 children, born in the interval from the 1st. of April, 1951, to the 31st. of March, 1952, composed of 160 boys and 129 girls. Part of these children, 204 in number, were in attendance at a kindergarten in April, 1957, and the rest, 85 in number, were in the first grade of an elementary school in April, 1958, both institutions located in Takata City, Niigata Prefecture, in the central 
part of Japan. Therefore, 204 kindergarten children were subjected to chronological investigations of 10 years, while grade school children to 9 years, covering from 5 or 6 years to 14 years.

An annual radiography of these subjects was effected under the following conditions. Selecting the upper and lower anterior regions and the upper and lower molar regions on the left and right sides, the intraoral radiography was used with 6-10 dental films isometrically and, where neccessary for specific purposes, standardized radiographic technic was employed. The following conditions were observed at the time of radiography.

\subsection{Dental X-ray apparatus.}

It had the capability of $65 \mathrm{kVp}(\mathrm{H} . \mathrm{V} . \mathrm{L}: \mathrm{Al} 1.6 \mathrm{~mm}), 10 \mathrm{~mA}$ and F. F. D. was $18 \sim 20 \mathrm{~cm}$.

\subsection{X-ray films used.}

From the first to the third years of observations baby-size films were used for the radiography of molar region but from the fourth year onward, ordinary periapical films were used.

\subsection{Development of X-ray films.}

In developing X-ray films thus taken, the authors followed the development procedures as instructed.

\subsection{Control test piece.}

For the twofold purpose of comparing the alveolar bone patterns exactly and determining slight differences in the density of films from year to year, a control test piece made of 5-layer Ni-Cr alloy plate (thickness: $0.2 \mathrm{~mm}$ ) step wedge was pasted on a border of the film every time radiography was taken. When neccessary, film density of the alveolar bone was calibrated comparing with each portion of the control test piece by microphotometry.

\subsection{Sorting and storage of film files.}

As every packet contained two films, the two identical film files were obtained. One set of film file was stored for permanent keeping and the other was used for photographic printing for presentation at an academic conference.

A series of 6 films taken of one subject every year were assorted with a filmmount in sequence and held in place by means of a Scoth tape. These were chronologically filed in the large Manila folder and classified in terms of the number of postnatal months, and they were given the serial numbers.

To insure the accuracy of radiographic interpretation, observations were mainly confined to the lower molar region and the data were often compared with those of the lower anteriors. Reasons for selecting the lower molar region were 1) radiographic image was sharp because of the fact that labio-lingual width of the jaw bone was smaller than other parts, 2) it was easier to applicate film into the mouth and thus 3) standardized radiographic procedure could be followed easily and accurately. 


\section{Results}

\subsection{Alveolar bone patterns at the normal successional replacement.}

Here the term normal replacement is used to refer to a case where the root of a deciduous precursor gives evidence of the physiological resorption or where even if there is slightly observed a periapical rarefaction of the precursor, the normal occlusion between it and the antagonist continues nearly up to the period of succession. 19 children, consisting of 11 boys and 8 girls, from 9 years 2 months to 10 years 2 months, all of whom were in the 4th. year grade of an elementary school in 1961 were chosen from among 289 subjects already mentioned above, because they were judged to correspond to our concept of the normal successional replacement. Their roentgenographs revealed that their $\overline{\mathrm{P}_{1}}$ or $\overline{\mathrm{P}_{2}}$ was in the process of eruption. With this selective sample of 19 children, standardized radiography was taken of the lower molar region once in every 3 months in order to carry out detailed observations of changes in the alveolar bone patterns attendant upon the eruption of permanent teeth.

For the ease of observational purposes, the duration of permanent eruption was divided into three stages as follows (Table 1).

The normal first stage :

The period at which the bone crypt has disappeared corresponding to the maximal width of the successor or over. In this stage, when the deciduous tooth is replaced by its successor through the exhausting of root resorption and shedding, pericoronal part of the bone crypt disappears to a large extent. In this instance, the bone crypt from the part of the maximal width of a successor to its cervix will remain in the shape of cup and the same phenomenon is also observed in the crests of the interalveolar septum between it and its adjacent teeth. One cannot yet discern clearly cancellous patterns of the alveolar bone and lamina dura of the root surface. Periodontal space is difficult to be observed and, therefore, border structure between the bone and corresponding root is still obscure. See Fig. 1, 1.

The normal second stage :

The period at which a successor has not yet formed a contact point with its approximal permanent teeth that have already completed eruption. In proportion to the degree of permanent eruption, the alveolar bone in the surrounding part of the permanent tooth cervix proliferates and the crest will change from the shape of cup to run horizontally, that is, orthogonally to the tooth axis. At this stage, radiographic appearances of the trabecular arrangements, lamina dura of the root surface and periodontal space will increase in clarity but as yet they do not have definite formations. See Fig. 1, 2.

The normal third stage :

The period at which eruption of a successor has been completed. Here a successor has formed a definite contact point with its approximal permanent teeth that have already completed their eruption. The alveolar crest has changed from the shape of cup to one running horizontally - orthogonally to the tooth axis. The radiographic image of the alveolar crest has much gained in clarity even in obscure spots at the former stages and the trabecular arrangements are fairly definitely observed. The alveolar crest has been formed at the location within $1 \mathrm{~mm}$ from the cemento-enamel junction. See Fig. 1, 4. 
Fig. 1. A case of typical normal successional replacement and its transforming pattern of the alveolar crest (Y. N., female)

(Radiograms
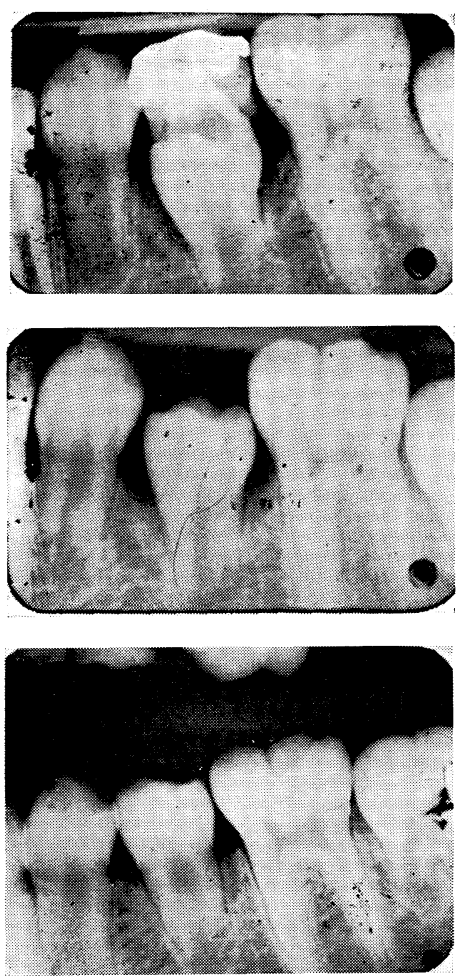

11.3

$(135)$

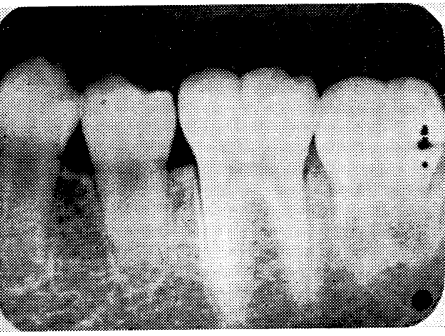

11.6

(138)

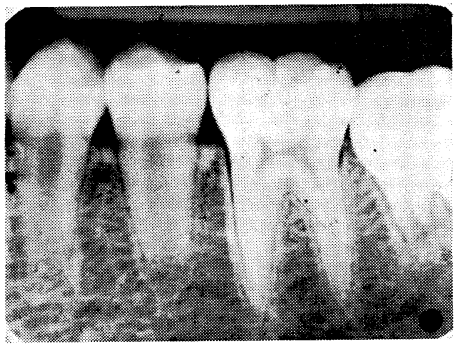

11.12

$(144)$

Note: In these figures, unmarked figures indicate years and months of children under survey. For example, 10.8 is to be read as 10 years 8 months. Figures in the round brackets give the conversion in postnatal months.
(Tracings)
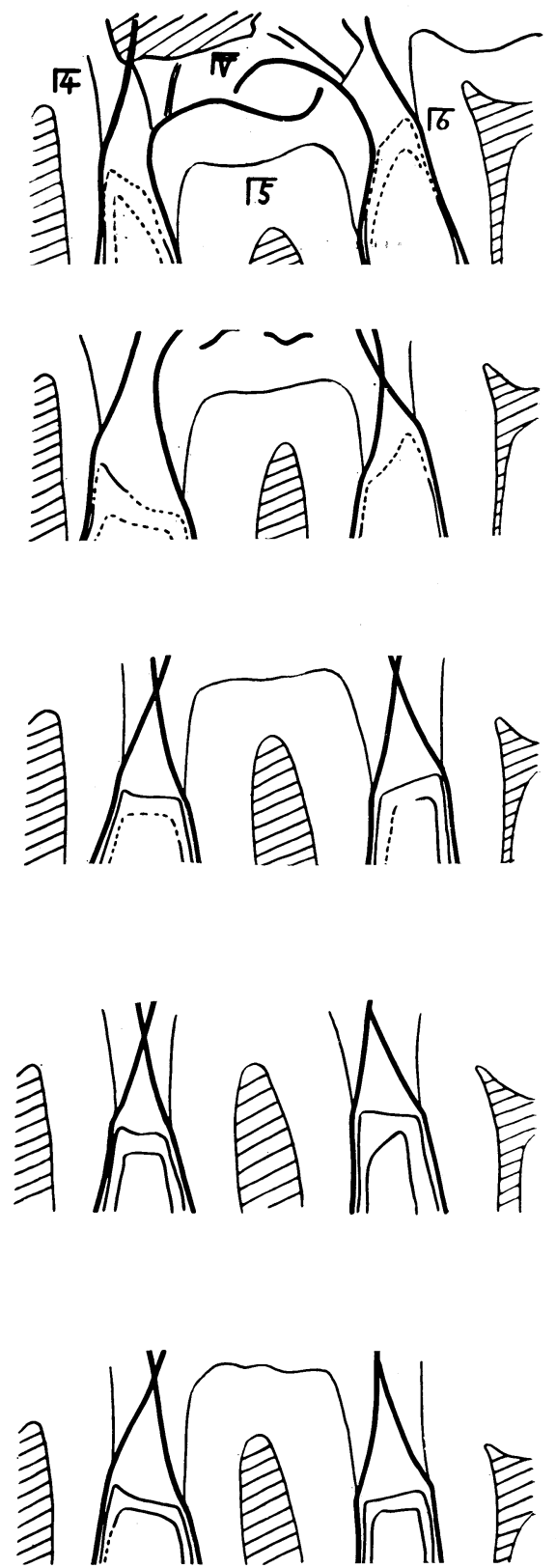
Fig. 2. Transforming pattern of the alveolar crest in case of remaining of root split on the eruptive way (T. H., male)

(Radiograms)
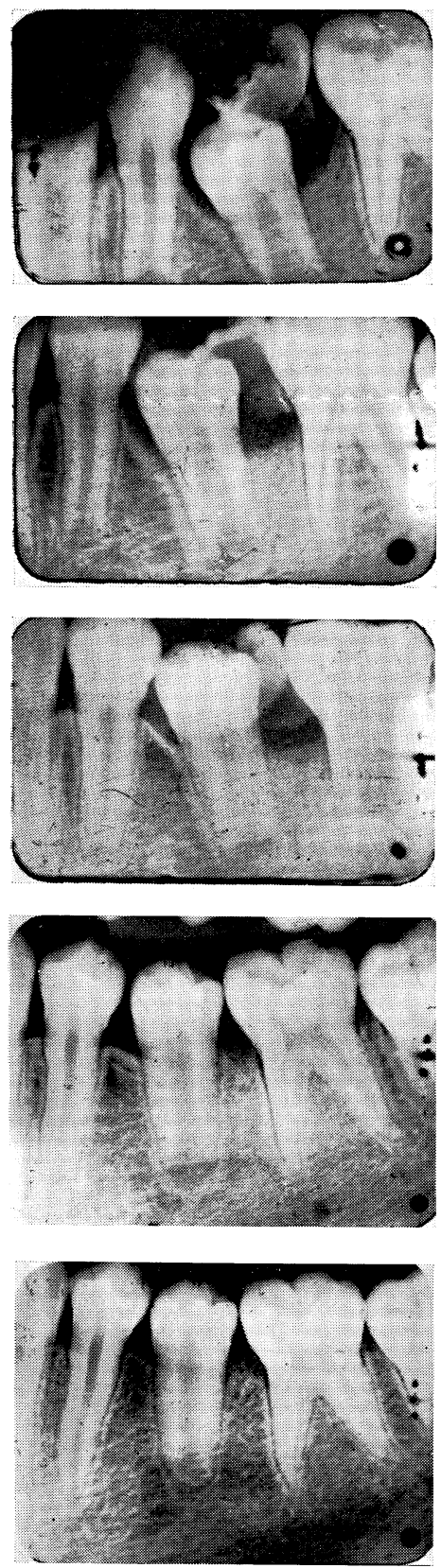

10.3

(123)

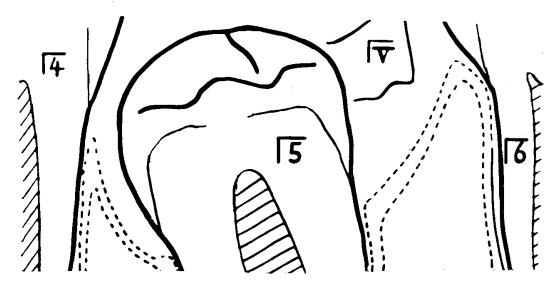

10.6

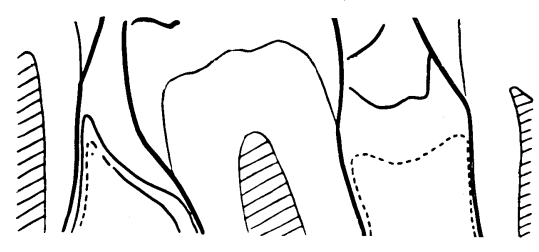

10.10

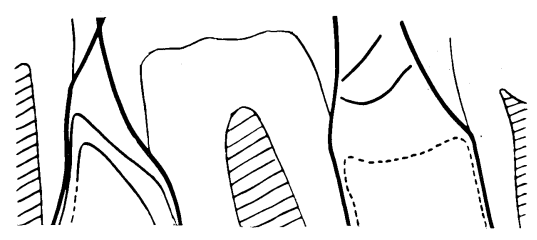

11.1

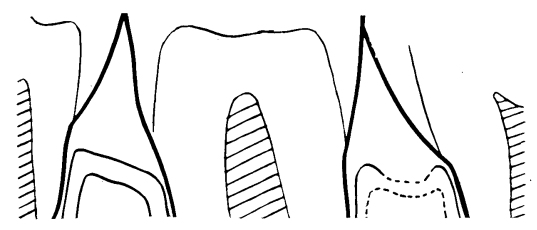

11.10

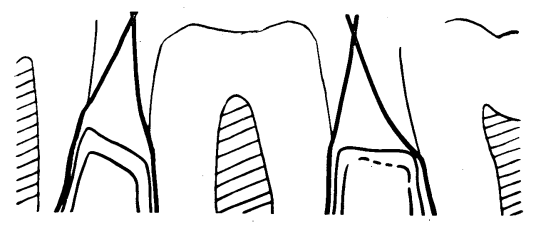




\subsection{Alveolar bone patterns at the abnormal successional replacement.}

The manner in which the deciduous teeth are replaced by their successors is greatly effected by the existence of the pathological rarefaction in their periapical region or otherwise. In some cases, root resorption of the deciduous teeth goes on despite the pathological periapical rarefaction to be finally in eruption of the permanent teeth. Here the same alveolar bone pattern will be produced as is the case of the normal replacement, but not infrequently there are found splits of the deciduous root which seem to interfere mechanically with the eruption of permanent dentition. Great differences are recognized as regards formation of the alveolar bone on the side in which a split of the deciduous root remains as compared with the other side having no split in it.

In order that effects of the split of the deciduous root to the alveolar bone patterns would be observed, selection was made of 20 children, 10 boys and 10 girls, in the age bracket of 7 years 2 months to 10 years 2 months, whose $\overline{\mathrm{P}_{1}}$ or $\overline{\mathrm{P}_{2}}$ was in the process of eruption under the conditions of their growth being interferred with by the remaining root splits.

They were subjected to standardized radiography taken from among those of an annual observation once in every 3 months, and were used for the purpose of comparison with the normal replacement to insure accuracy.

These conditions of children were classified into the following three stages for the sake of convenience, as in 3.1.

\subsubsection{The abnormal first stage:}

Cases in which the deciduous root remains directly in the alveolar socket.

When a split of the deciduous root remains in the eruptive way or because of its pathologic conditions, there is often found an abnormal defect in the alveolar bone crest. When the bone structure in this region is compared, in the same individual, with the bone structure of the opposite side which suffers from no periapical rarefaction, formation of both the trabecular arrangements and lamina dura of the root surface is alike indefinite. These root splits which remain in the eruptive way often influence the direction in which eruption occurs and in not a few cases the direction of longitudinal axis of the tooth will be affected (Fig. 2, $1 \& 2$ ).

\subsubsection{The abnormal second stage :}

Cases in which the deciduous root remains are attached to the dental arch only with the gingiva through as the result of their root resorption. When the root has been resorbed and its direct contact with the alveolar bone is lost, the production of bone will occur in the defective part of alveolar ridge, gradually attaining to the full alveolar crest (Fig. 2,3).

\subsubsection{The abnormal third stage:}

Cases in which deciduous root split is eliminated. The children in this stage have permanent teeth which tend to develop in the normal direction from the axis inclination previously produced under pressure of deciduous root splits and an improvement is also observed in the alveolar bone. That is to say, alveolar bone close to the cervix on the inclining side will increase and although there is some pathologic condition associated with resorption on that side, the whole will attain to a balanced growth. However, growth is slower on the pathologically affected side of the alveolar bone as compared with the healthy side (Fig. 2, 4 and 5). 


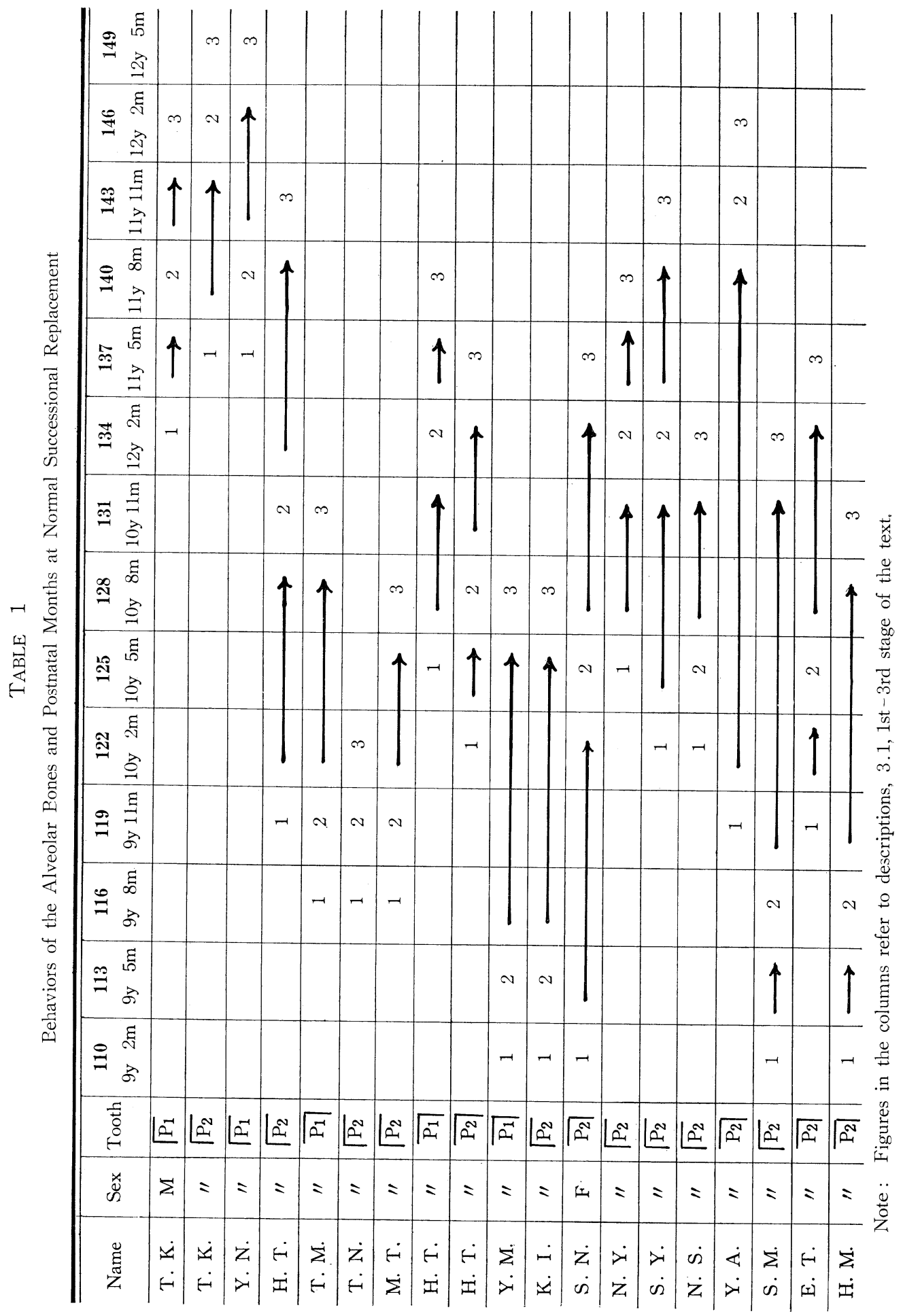




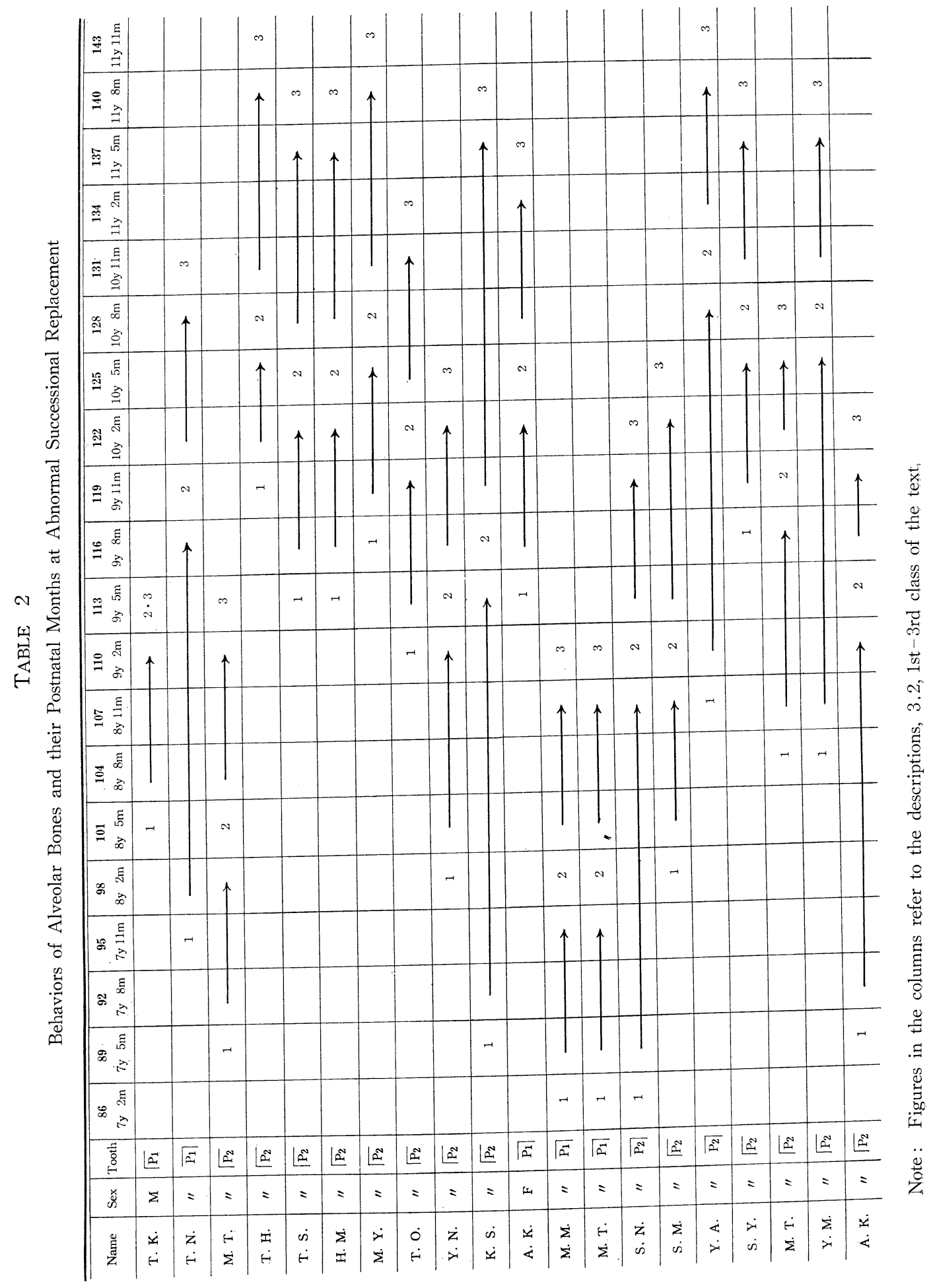


Another case of the abnormal replacement, which accounts for not a few incidences, is that suppurative absorption of the alveolar bone in proximity to the deciduous root is remarkable and the carious destruction of deciduous crown is to an extensive degree and, for this reason, deciduous precursors shed and become lost at a much earlier period than is accepted as the period of the normal successional replacement (Table 2). As will be discussed in more detail in the ensuing section, successors in these cases will usually remain inside the bone crypt and do not easily erupt in the majority.

\subsection{Behaviors of the alveolar bone due to an early loss af deciduous teeth.}

As has been already discussed, the authors often encounter cases in which deciduous precursors shed and become lost much earlier than the normal replacing period, through some kind of pathologic resorption of their root. In these instances, it is sometimes observed that covering part of crypt on the successors are greatly damaged by a periapical osteitis of the precursors and, as a result, successors will erupt sufficiently early irrespective of the root formation. On the other hand, when the bone crypt remains undamaged the majority of successors will stay within the bone and will not easily erupt.

The natural assumption was that there must be differences on the part of the alveolar bone behavior through an early loss of deciduous precursors as distinct from the normal replacement.

\subsubsection{Premature loss of precursors and premature eruption of permanent successors.}

For the purpose of this part of the survey, selection was made from among those used for the foregoing studies. 8 boys and 7 girls, ranging in age from 7 years to 8 years 3 months, whose $\overline{\mathrm{P}_{1}}$ or $\overline{\mathrm{P}_{2}}$ had erupted in the second or the third year of the survey were chosen. The samples consisted of $14 \overline{\mathrm{P}_{1}}$ and $1 \overline{\mathrm{P}_{2}}$ (Table 3 ).

3.3.2 Cases in which there was the premature loss of deciduous teeth but the permanent teeth erupted in the neighborhood of the average eruptive period.

30 boys and 18 girls, 48 subjects altogether, were subjected to this examination. Either $\overline{\mathrm{P}_{1}}$ or $\overline{\mathrm{P}_{2}}$ in these samples had been lost or disappeared by the third year of the survey with the result that the successors remained in the bones. The teeth specimens were $51 \overline{\mathrm{P}_{1}}$ and $63 \overline{\mathrm{P}_{2}}$ (Table $4, \mathrm{~A}, \mathrm{~B}, \mathrm{C}$ ). With these samples, the following findings came to light.

3.3.2.1 Even if the deciduous teeth had been prematurely lost, as long as the bone crypt was intact without any damage, the successors remained in the bones and erupted at their averageal eruptive period.

3.3.2.2 Following the early loss of deciduous teeth, the formation of alveolar bones around the successors will undergo the following processes.

a. If there does not take place a large alveolar bone resorption at the early loss of deciduous teeth, that spot will remain fairly even. In this period, a successor has completed the calcification of only part of the root or coronal portion. The bone crypt of this successor gives globular appearances and a layer of healthy bone is observed between this and the alveolar crest (Fig. 4, 1, 2).

b. In proportion to the advance in the formation of permanent root, the form of bone crypt will gradually change from globular to inverted $U$ appearances extending downward. When that successor erupts, alveolar bone around the coronal portion will disappear and the distance between the alveolar crest and the top of cusp will be much reduced. Although a radiographic image of the neighboring alveolar bone is obscure, 
TABLE 3

Postnatal Months of Premature Eruption of Succedaneous Teeth

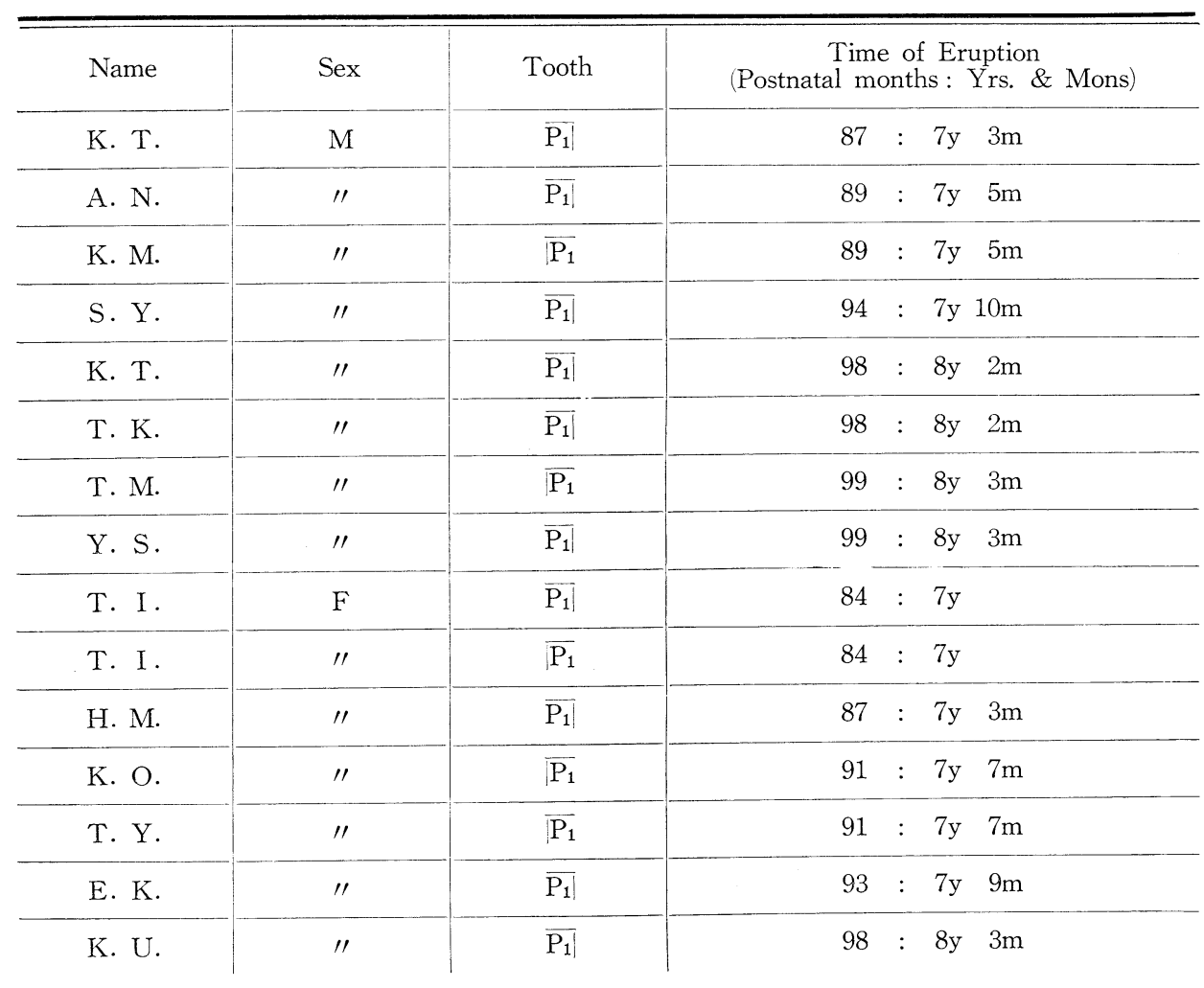

TABLE 4

Remaining Durations of Successors in the Bone after Premature Loss of Precursors $\left(51 \overline{\mathrm{P}}_{1}, 63 \overline{\mathrm{P}}_{2}=114\right)$

\begin{tabular}{|c|c|c|c|c|c|c|c|c|}
\hline \multicolumn{2}{|l|}{ Duration (Yrs) } & 1 & 2 & 3 & 4 & 5 & 6 & Total \\
\hline A. 1st year of survey & $\overline{\mathrm{P}}_{1}$ & 0 & 0 & 2 & 8 & 7 & 3 & 20 \\
\hline (Number of teeth) & $\overline{\mathrm{P}}_{2}$ & 0 & 1 & 1 & 3 & 9 & 3 & 17 \\
\hline B. 2nd year of survey & $\overline{\mathrm{P}}_{1}$ & 2 & 3 & 5 & 8 & 8 & - & 26 \\
\hline (Number of teeth) & $\overline{\mathrm{P}}_{2}$ & 1 & 2 & 1 & 9 & 16 & - & 29 \\
\hline \multirow{2}{*}{$\begin{array}{l}\text { C. 3rd year of survey } \\
\text { (Number of teeth) }\end{array}$} & $\overline{\mathrm{P}}_{1}$ & 0 & 1 & 3 & 1 & - & - & 5 \\
\hline & $\overline{\mathrm{P}}_{2}$ & 0 & 1 & 10 & 6 & - & - & 17 \\
\hline
\end{tabular}

the bone crypt is clearly discernible on the film as a white line (Fig. 4, 5).

c. When the calcification of the permanent alveolar bone further advances, the bone crypt will expand itself to the root apex and the eruption will be promoted. The pericoronal bone of successor will still disappear and the alveolar crest and bone crypt 
Fig. 3. Comparison on transforming pattern of the alveolar crest between normal and accelerated replacement (M. Y., male)

Normal replacement
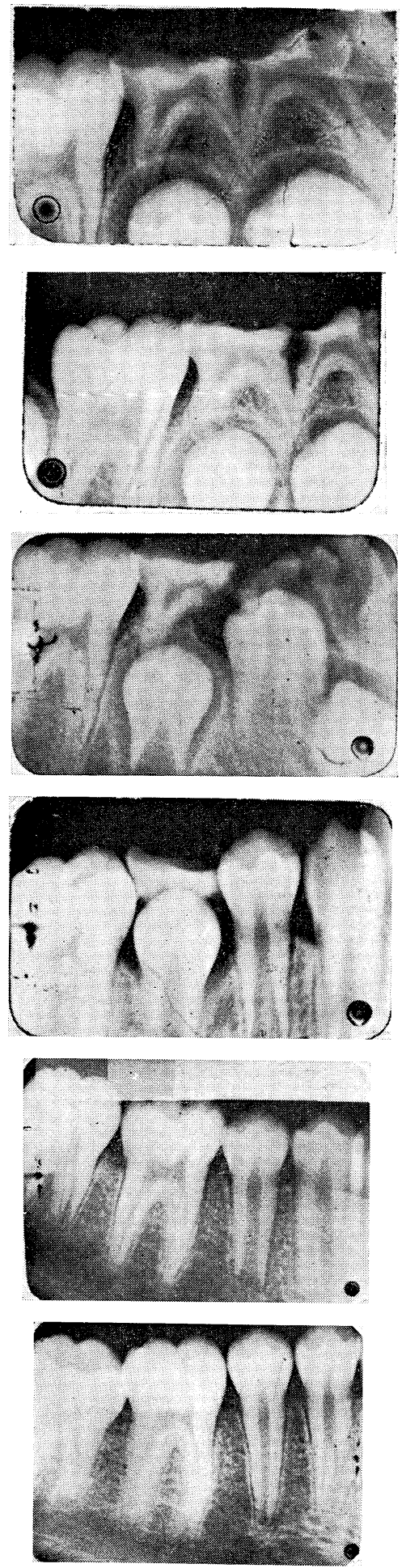

Premature eruption of the precursor 1

6.8

(80)

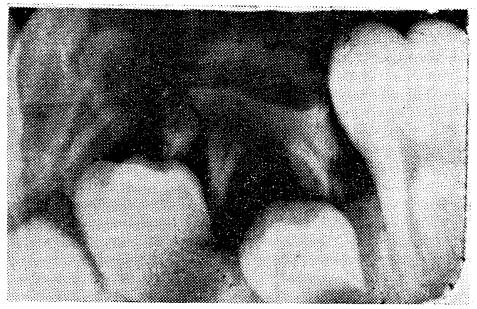

2

7.8

(92)

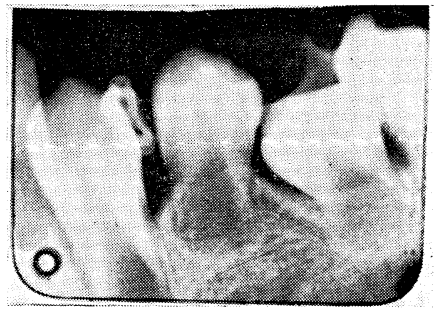

3

8.8

(104)

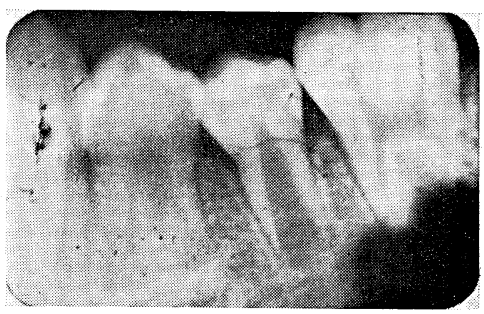

4

9.8

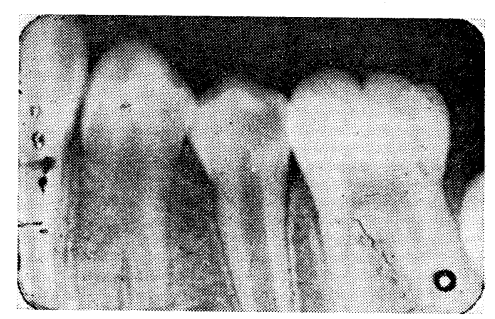

5

10.8

(128)

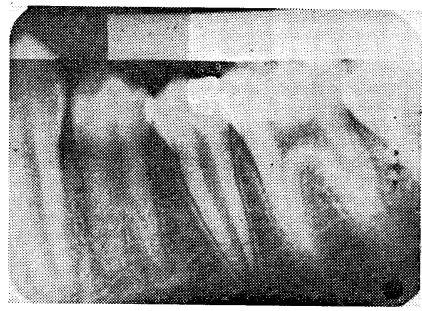

6

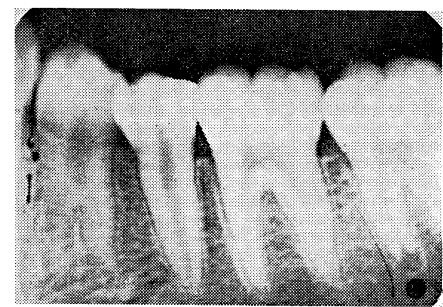

Note: These represent the corresponding antimeres in one individual. 
Fig. 4. Premature loss of deciduous teeth and the forming pattern of alveolar crest $\left(\mid \overline{\mathrm{m}_{1}}\right.$ and $\left|\overline{\mathrm{P}_{1}} ;\right| \overline{\mathrm{P}_{2}}$. T. T., male $)$

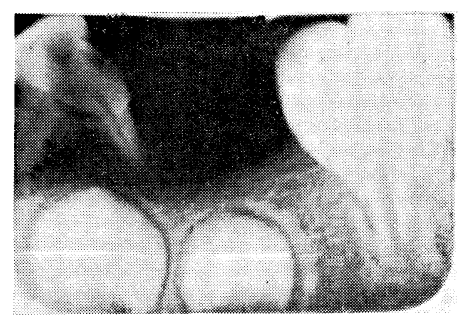

$7.1(85)$

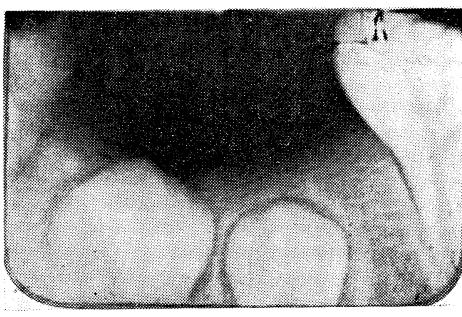

$8.1 \quad(97)$

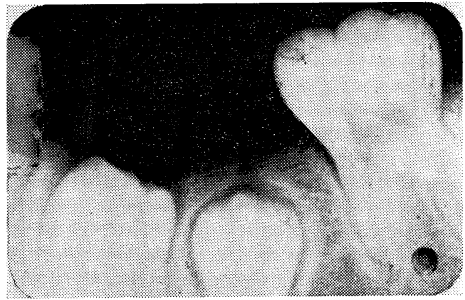

$9.1(109)$

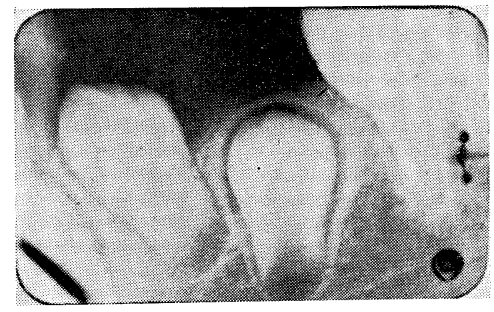

$10.1(121)$

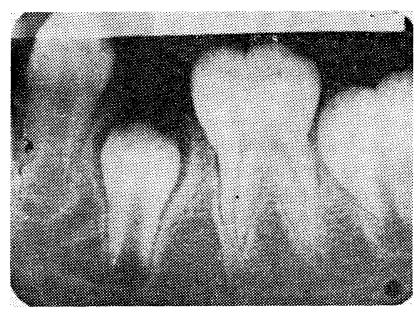

11.1 (133)

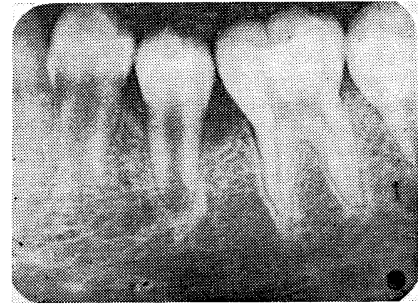

$12.1(145)$ 
Fig. 5. Transforming pattern of the bone structure into the alveolar crest from their crypt in lower anterior region (E. K., female)

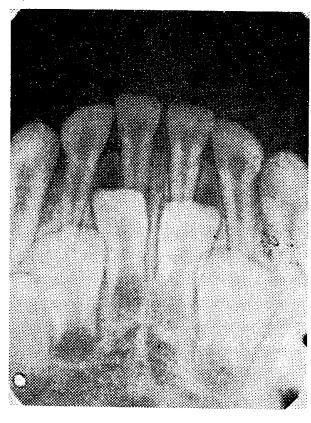

$5.3(63)$

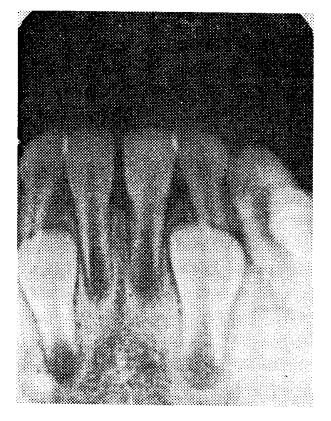

$6.3(75)$

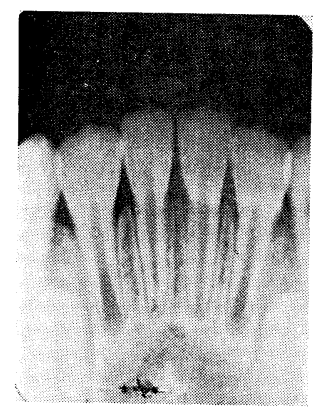

$7.3(87)$

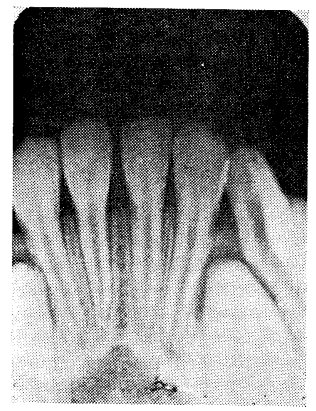

$8.3(99)$ 
in the root portion will merge with one another to such an extent where they will appear as a thin white line. When this white line is destroyed, the state of the alveolar emergence, so-called "bone eruption", will occur and the formation of the pericoronal bone will proceed in the usual stages as is the case with the normal replacement (Fig. 4, 6).

\subsection{Alveolar bone patterns at the successional replacement in the lower anterior region.}

For the purpose of this period of the survey, use was made of 27 boys and 23 girls, who had experienced the eruption of $\overline{I_{1}}$ or $\overline{I_{2}}$ after ages from 7 years 3 months to 8 years 2 months. Changes in the alveolar bone patterns attendant upon the eruption were compared with those in the lower premolar region. The crest of interalveolar septum in the lower anterior region is different from that of the premolar region in terms of the contact and morphology of teeth concerned. That is, while the crest of interalveolar septum in the former has an appearance of the inverted $\mathrm{V}$, that in the latter has an appearance resembling the inverted $U$ or 凸 shape. However, difference in the form of crest of interalveolar septum does not mean any fundamental difference in the processes involved in the formation of alveolar bone. Moreover, as the lower anterior region possess usually much fewer dental caries of the precursors as against the lower premolar region, the case of abnormal replacement brought about, for instance, by the suppurative resorption of alveolar bone is rare, the majority of these teeth undergoing the normal replacement. The following series of radiograms give some representative cases of the alveolar bone formation taken in the present survey.

\section{Explanations of the Radiograms :}

1. On this film (5 years 3 months) taken in the first year of the survey, the resorption of the apex of $\overline{i_{1}} \mid$ is observed to about $1 / 3$ and also a slight degree of resorption is seen on the alveolar bone corresponding to the edge of $\overline{I_{1} \mid I_{1}}$. However, there is no particular finding to be noted as regards the bone crypt (Fig. 5, 1).

2. On this film (6 years 3 months) taken in the second year of the survey, one observes that the deciduous teeth had already shed and $\overline{\mathrm{I}_{1} \mid \mathrm{I}_{1}}$ erupted. But the bone crypt of $\overline{\mathrm{I}_{2} \mid \mathrm{I}_{2}}$ was still intact.

In connection with the eruption of $\overline{\mathrm{I}_{1} \mid \mathrm{I}_{1}}$, the alveolar crest gives a cuplike appearance and the top of interalveolar septum is acute as if the inverted V. On the other hand, the appearance of progresses of the periodontal space, lamina dura corresponding to the root surface and trabecular pattern of the bone still obscure. At this stage, their formations are merely known (Fig. 5, 2).

3. Taken in the third year of the survey (7 years 3 months), this film indicates the eruption of $\overline{I_{2} \mid I_{2}}$. In proportion to the progress of the eruption of $\overline{I_{1} \mid I_{1}}$, alveolar bone in the neighborhood of the cervix tends to increase and the top of interalveolar septum changes its form from the sharp to the round. The alveolar bone in this region increases and the periodontal space, lamina dura corresponding to the root surface and trabecular patterns of the bone have gradually become definite (Fig. 5, 3).

4. This film taken in the fourth year of the survey does not differ greatly from the foregoing one. The outline of alveolar crest has become much more round. The interalveolar septa between $\overline{I_{2}} \mid$ and $\overline{I_{1}} \mid$ and between $\mid \overline{I_{1}}$ and $\mid \overline{I_{2}}$ became thinner and their lamina dura corresponding to the root surfaces have gained in texture (Fig. 5, 4).

3.5 Alveolar bone patterns where permanent teeth complete their eruption after twisting: or inclining in the bone.

In the accepted knowldege of scholars, the rotated tooth has been given as one of 
the malpositions of teeth in a broad sense. Although the causes for rotation are by no means clear enough, one reason is assigned to the confusion of dental arch at the time of eruption due to the retrogradal contraction of jaw bone and another is that the tooth which had erupted in the normal position may have secondarily moved out of alignment on account of some anomaly in occlusion or the missing of approximal teeth.

The authors were here concerned with the behaviors of rotated teeth immediately before and after the eruption with reference to changes in the alveolar bone to the completion of eruption.

The rotation of teeth can be considered in three aspects : one is twisting which is the rotation to the long axis of tooth, the second is labio-lingual inclination which takes place to the mesio-distal axis of tooth and the third is mesio-distal inclination which is the rotation to the labio-lingual axis of tooth. Of these three kinds on rotation, however, the diagnosis of labio-lingual inclination is often difficult on a radiogram and for this reason, efforts were confined to those rotated teeth in twisting and mesio-distal inclination classes. It is of course that these rotated teeth do not occur singly, but appear quite often in association with their approximal teeth.

\subsubsection{Tristing of teeth}

8 boys and 11 girls with the total of 19 teeth consisting of $9 \overline{\mathrm{P}_{1}}$ and $10 \overline{\mathrm{P}_{2}}$ were subjected to the investigation of twisting.

The degrees of twisting were determined as follows.

3.5.1.1 The line linking the buccal and lingual cusps happens to run in parallel to the long axis of a precursor or approximal precursor. This is termed normal $(\mathrm{N})$.

3.5.1.2 When twisting is less than $90^{\circ}$, it is represented as mesial twisting $\left(\mathrm{M}^{1} / 2\right)$ or distal twisting $\left(\mathrm{D}^{1 / 2}\right)$.

3.5.1.3 When twisting is at $90^{\circ}$, it is represented as mesial twisting $\left(\mathrm{M}_{1}\right)$ or distal twisting $\left(\mathrm{D}_{1}\right)$.

3.5.1.4 A twisting exceeding $90^{\circ}$ was not observed in this study (Table 5).

1. As shown on Table 5, those teeth had already shown twisting since the early stage of calcification of the coronal surface in the bone crypt. The majority of them were in mesial twisting.

2. Although it is reasonable to infer effect of the neighboring teeth, i. e., mesial inclination or mesial movement of $\overline{\mathrm{M}}_{1}$, and changes attendant upon the eruption of $\overline{\mathrm{C}}$, $\overline{\mathrm{P}_{1}}$ and $\overline{\mathrm{P}_{2}}$ on the twisting of developing $\overline{\mathrm{P}_{1}}$ or $\overline{\mathrm{P}_{2}}$ within the bone crypt, as a matter of fact not a few teeth were observed that have freely rotated within the bone crypt without coming under any of these effects. It was not possible to assign any definite cause to them.

3. By the time when calcification of the coronal part of teeth was completed, some of the teeth had twisted irregardless of the neighboring alveolar bones. But their relationship with the neighboring alveolar bones became much greater in proportion to the advance of calcification of the root. In this stage of affairs, teeth could not rotate freely within the bone crypt and they tended to erupt in the twisted state unless there was some effect of the existing of precursor or approximal teeth (Table 5, Fig. 6).

\subsubsection{Inclination of teeth}

11 boys and 13 girls with the total of 24 teeth consisting of $18 \overline{\mathrm{P}_{1}}$ and $6 \overline{\mathrm{P}_{2}}$ were used for this part of the study. 
TABLE 5

Twisting of the Succedaneous Teeth

a. Mesial twisting

\begin{tabular}{|c|c|c|c|c|c|c|c|c|c|}
\hline \multirow{2}{*}{ Name } & \multirow{2}{*}{ Sex } & \multirow{2}{*}{ Kinds } & \multicolumn{7}{|c|}{ Yrs. of observation } \\
\hline & & & 1 & 2 & 3 & 4 & 5 & 6 & 7 \\
\hline K. K. & $\mathrm{M}$ & $\overline{\mathrm{P}_{1}}$ & $\mathrm{~N} \quad(0)$ & M1 $(0)$ & $\mathrm{M} \frac{1}{2}(0)$ & $\mathrm{M} \frac{1}{2}(0)$ & $\mathrm{M}^{\frac{1}{2}}\left(\frac{2}{3}\right)$ & M1 (E) & M 1 \\
\hline M. U. & $\prime \prime$ & $\overline{\mathrm{P}_{1}}$ & $\mathrm{M}_{\frac{2}{2}}^{\frac{1}{1}}(0)$ & $M \frac{1}{2}(0)$ & $M \frac{1}{2}\left(\frac{1}{3}\right)$ & $\mathrm{N} \quad(\mathrm{E})$ & $\mathrm{N}$ & $\mathrm{N}$ & $\mathrm{N}$ \\
\hline S. D. & $\prime \prime$ & $\overline{\mathrm{P}_{1}}$ & - & $M \frac{1}{2}\left(\frac{2}{3}\right)$ & $M \frac{1}{2}(1)$ & $\mathrm{M} \frac{1}{2}-(\mathrm{E})$ & $\mathrm{N}$ & $\mathrm{N}$ & $\mathrm{N}$ \\
\hline K. H. & $\prime \prime$ & $\overline{\mathrm{P}_{1}}$ & $\mathrm{M}^{-\frac{1}{2}}(0)$ & $M \frac{1}{2}(0)$ & $\mathrm{M} \frac{1}{2}(0)$ & $\mathrm{M} 1(0)$ & $M \frac{1}{2}(0)$ & $M \frac{1}{2}(0)$ & $\mathrm{N} \quad(\mathrm{E})$ \\
\hline N. T. & $\prime \prime$ & $\overline{\mathrm{P}_{1}}$ & - & $\mathrm{M} \frac{1}{2}(0)$ & $\mathrm{M} \frac{1}{2}(1)$ & $M 1(1)$ & M 1 (E) & $M \frac{1}{2}$ & $M \frac{1}{2}$ \\
\hline S. S. & $\prime \prime$ & $\overline{\mathrm{P}_{2}}$ & - & - & $\mathrm{M} 1(0)$ & $\mathrm{M} 1(1)$ & $\mathrm{M} 1(0)$ & M1 $(0)$ & $\mathrm{M} 1(0)$ \\
\hline S. S. & $\prime \prime$ & $\overline{\mathrm{P}_{2}}$ & - & $\mathrm{M} \frac{1}{2}(0)$ & $\mathrm{M} \frac{1}{2}(0)$ & $\mathrm{M}_{2}^{\frac{1}{2}}(0)$ & $\mathrm{M} \frac{1}{2}(0)$ & $\mathrm{M}_{2}^{-\frac{1}{2}}-(0)$ & M1 10$)$ \\
\hline M. M. & $\mathrm{F}$ & $\overline{\mathrm{P}_{1}}$ & - & $N \quad(0)$ & $M \frac{1}{2}(1)$ & M 1 (1) & $\mathrm{M} \frac{1}{2}(\mathrm{E})$ & $\mathrm{N}$ & $\mathrm{N}$ \\
\hline R. I. & "l & $\overline{\mathrm{P}_{1}}$ & $\mathrm{~N} \quad(0)$ & $M \frac{1}{2}(0)$ & $\mathrm{N} \quad(0)$ & M1 (0) & $\mathrm{M} \frac{1}{2}(1)$ & $M \frac{1}{2}(E)$ & $\mathrm{M} \frac{1}{2}$ \\
\hline K. Y. & $\prime \prime$ & $\overline{\mathrm{P}_{1}}$ & $\mathrm{M} \frac{1}{2}(0)$ & $\mathrm{M} \frac{1}{2}\left(\frac{1}{3}\right)$ & $M \frac{1}{2}\left(\frac{2}{3}\right)$ & $\mathrm{M} \frac{1}{2}(1)$ & $\mathrm{N} \quad(\mathrm{E})$ & $\mathrm{N}$ & $\mathrm{N}$ \\
\hline Y. K. & $\prime \prime$ & $\overline{\mathrm{P}_{2}}$ & $\mathrm{M}_{2}^{\frac{1}{2}}(0)$ & $M \frac{1}{2}(0)$ & $M \frac{1}{2}\left(\frac{2}{3}\right)$ & $\mathrm{M}^{-\frac{1}{2}}(\mathrm{E})$ & $M \frac{1}{2}$ & $M \frac{1}{2}$ & $\mathrm{M}^{\frac{1}{2}}$ \\
\hline K. N. & $\prime \prime$ & $\overline{\mathrm{P}_{2}}$ & - & $M \frac{1}{2}(0)$ & $\mathrm{M} \frac{1}{2}(0)$ & $\mathrm{M} \frac{1}{2}(1)$ & $M \frac{1}{2}(E)$ & $M \frac{1}{2}$ & $M \frac{1}{2}$ \\
\hline K. Y. & $\prime \prime$ & $\overline{\mathrm{P}_{2}}$ & - & $M \frac{1}{2}(0)$ & M 1 (0) & $M \frac{1}{2}(0)$ & M1 (0) & M $1(0)$ & $\mathrm{M} 1(0)$ \\
\hline K. Y. & $\prime \prime$ & $\overline{\mathrm{P}_{2}}$ & - & M 1 (0) & $\mathrm{M} \frac{1}{2}(0)$ & $M \frac{1}{2}(0)$ & $\mathrm{M} \frac{1}{2}(0)$ & $M \frac{1}{2}(0)$ & $\mathrm{M} \frac{1}{2}(0)$ \\
\hline Y. T. & $\prime \prime$ & $\overline{\mathrm{P}_{2}}$ & $\mathrm{M}_{2}^{\frac{1}{2}(0)}$ & $\mathrm{M} \frac{1}{2}(0)$ & $\mathrm{M} 1(0)$ & M1 (0) & $M \frac{1}{2}(1)$ & $\mathrm{M} 1(\mathrm{E})$ & M 1 \\
\hline Y. T. & $\prime \prime$ & $\overline{\mathrm{P}_{2}}$ & $\mathrm{M} \frac{1}{2}(0)$ & $\mathrm{M} \frac{1}{2}(0)$ & $\mathrm{M} \frac{1}{2}(0)$ & $\mathrm{M} \frac{1}{2}(0)$ & $M \frac{1}{2}(1)$ & $\mathrm{M} \frac{1}{2}(\mathrm{E})$ & $\mathrm{M} \frac{1}{2}$ \\
\hline
\end{tabular}

\begin{tabular}{|c|c|c|c|c|c|c|c|c|c|}
\hline \multirow{2}{*}{ Name } & \multirow{2}{*}{ Sex } & \multirow{2}{*}{ Kinds } & \multicolumn{7}{|c|}{ Yrs. of observation } \\
\hline & & & 1 & 2 & 3 & 4 & 5 & 6 & 7 \\
\hline I. U. & M & $\overline{\mathrm{P}_{1}}$ & $\mathrm{D} \frac{1}{2}(0)$ & $\mathrm{N} \quad(0)$ & $\mathrm{D} \frac{1}{2}\left(\frac{1}{3}\right)$ & $\mathrm{N} \quad(\mathrm{E})$ & $\mathrm{N}$ & $\mathrm{N}$ & $\mathrm{N}$ \\
\hline E. S. & $\mathrm{F}$ & $\overline{\mathrm{P}_{2}}$ & $N \quad(0)$ & $\mathrm{D} \frac{1}{2}(0)$ & $\mathrm{D} \frac{1}{2}(0)$ & $\mathrm{D} \frac{1}{2}(0)$ & $\mathrm{D} \frac{1}{2}(0)$ & $\mathrm{D} \frac{1}{2}(0)$ & $\mathrm{D} \frac{1}{2}(1)$ \\
\hline K. S. & $\prime \prime$ & $\overline{\mathrm{P}_{2}}$ & - & $\mathrm{D} \frac{1}{2}(0)$ & $\mathrm{D} \frac{1}{2}(0)$ & D $1(0)$ & $\mathrm{D} \frac{1}{2}(1)$ & $\mathrm{N} \quad(\mathrm{E})$ & $\mathrm{N}$ \\
\hline
\end{tabular}

Note: Figures within the brackets ( ) indicate the disappearance of bone crypt on the occulusal surface of the teeth, while $E$ indicates eruption at the time specified. 
Fig. 6. Behaviors of the alveolar bones and twisting eruption of permanent teeth (A. S., male)

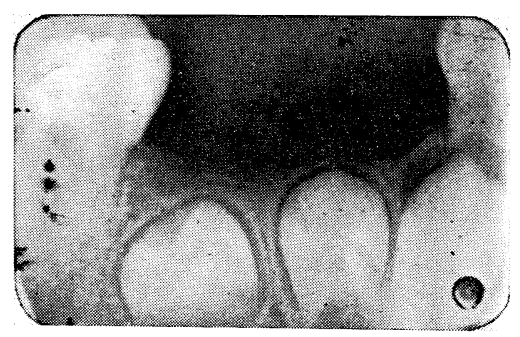

9.7

(115)
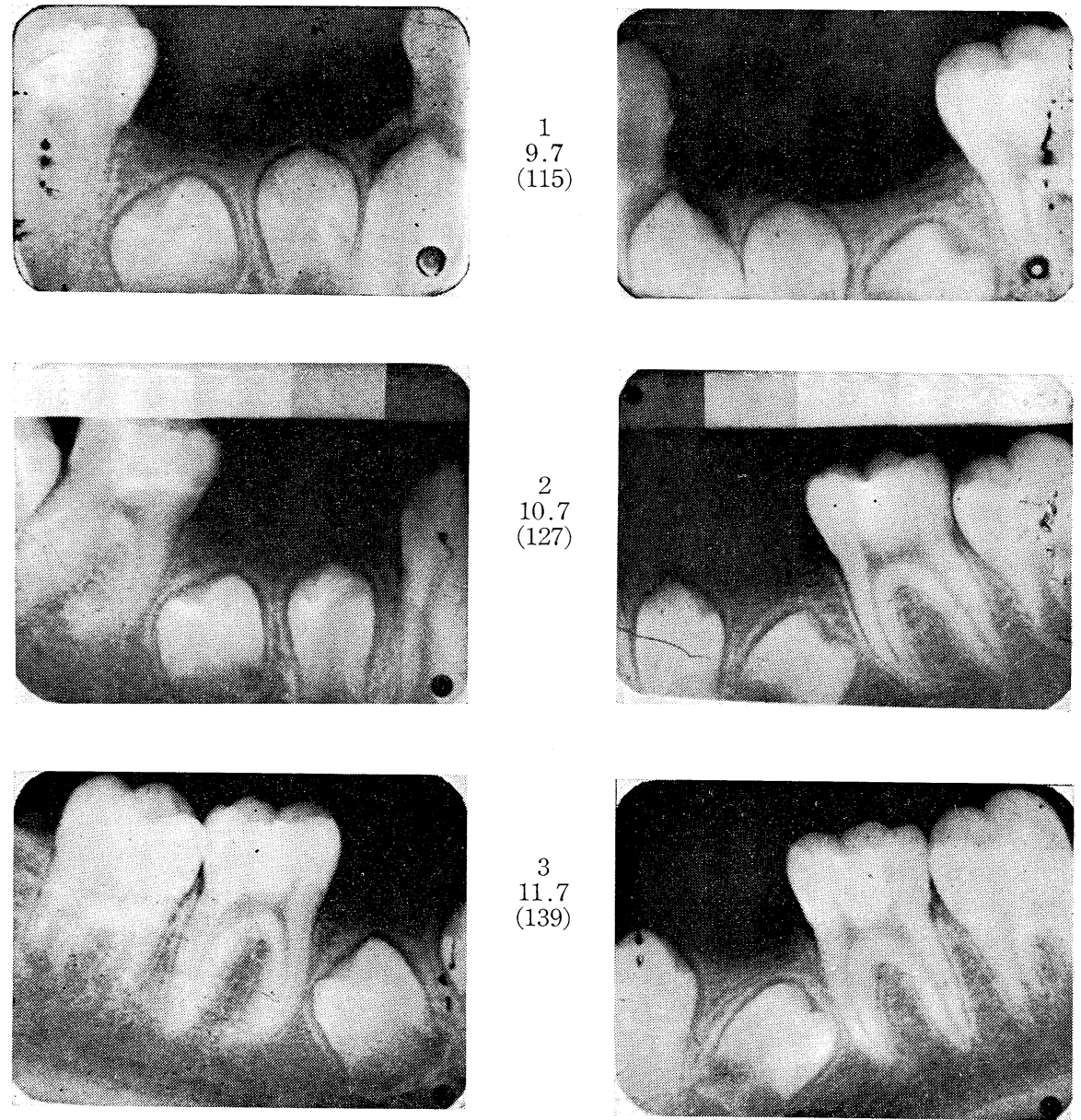

Note: These represent the corresponding antimeres in one individual. 
3.5.2.1 The degrees of inclination were determined by the following indications.

a. When the axis of $\overline{\mathrm{P}_{1}}$ or $\overline{\mathrm{P}_{2}}$ runs in parallel to that of a precursor, it is judged to be normal $(\mathrm{N})$.

b. Even if where a precursor is in the state of residue root or lost, the axis is used as a bench mark as long as $\overline{\mathrm{c} / \mathrm{c}}$ are normal.

c. In such cases where $\overline{\mathrm{c}}, \overline{\mathrm{m}_{1}}$ and $\overline{\mathrm{m}_{2}}$ are all in the state of residue roots or lost, linking of the two tips of the alveolar crest is used as a bench mark.

3.5.2.2 The inclinations thus measured were classified as follows.

a. Those found normal are normal $(\mathrm{N})$.

b. Those whose inclination is less than $30^{\circ}$ are represented as $\mathrm{m}^{1 / 3}$ or $\mathrm{d}^{1 / 3}$.

c. Those whose inclination is in the range of $30^{\circ}$ to $60^{\circ}$ are represented as $\mathrm{m}^{1 / 3}$ or $\mathrm{d}^{2} / 3$.

d. Those whose inclination is in the range of $60^{\circ}$ to $90^{\circ}$ are represented as $\overline{\mathrm{m}_{1}}$ or $\mathrm{d}_{1}$ respectively (Table 6 ).

1. Because of effect of a precursor or neighboring teeth, i. e., later retention of deciduous teeth, the mesial inclination of $\overline{\mathrm{M}_{1}}$ or the eruption of $\overline{\mathrm{c}}, \overline{\mathrm{P}_{1}}$ and $\overline{\mathrm{P}_{2}}$, changes may be brought about in the eruptive direction of $\overline{\mathrm{P}_{1}}$ or $\overline{\mathrm{P}_{2}}$. When a tooth has become inclined within the bone, volume of the alveolar bone on the inclining side will become larger as compared with that on the opposite side. In this connection, its cancellous pattern on a radiogram is more evident.

On the other hand, as the opposite side approximates $\bar{c}$ or $\overline{\mathrm{M}_{1}}$, the bone volume mainly on the mesial side of $\overline{\mathrm{P}_{1}}$ or mainly on the distal side $\overline{\mathrm{P}_{2}}$ will become smaller and, for this reason, particular bone structure here will be obscure on account of the interalveolar septum being indefinite or of the mere existence of lamellated bone.

2. When the eruptive direction of teeth is changed under various causes, density of the alveolar crest on the inclining side will increase as well as its thickness. But when such effects as the loss of precursors or the eruption of approximal teeth are eliminated, disparity in the thickness of alveolar crest between the inclining side and opposite side will disappear. Moreover, unless there exists some periapical rarefaction in a precursor both on the mesial and distal sides, the development and form of alveolar crest and lamina dura will approach the normal in proportion to the decrease in inclination (Table 6, Fig. 7).

\subsection{Alveolar bone trabeculation before and after the eruption of permanent teeth.}

The trabeculation seen in the sponginosa of alveolar bone are capable of being classified into various patterns in terms of spreading of bone trabeculae. Spreading patterns of bone trabeculae will become more definite in proportion to the advance in eruption of teeth. Clear radiographic apperances are obtained within 6 months or so from the completion of permanent eruption. Spreading patterns of cancellous sponginosa vary from individual to individual and, in addition to this, they are complex in structure, this fact rendering a precise classification quite difficult. It is also maintained that "Even in a healthy man the calcification of alveolar bone increases in proportion to the advance in age, resulting in more density of cancellous spaces and because of this, the bone structure will be rendered much obscured " [5] but, as far as the present survey was concerned, clear radiographic appearances were obtained because of the fact that subjects under examination were relatively close to the completion of the eruption of their permanent teeth. 
For the authors' purposes, radiograms were made of the anterior and posterior regions of the mandibles in 145 boys and 136 girls (281 in total) ranging in age from 11 years 3 months to 12 years 2 months. Careful selection was then made of these radiograms to obtain only those which could be accurately interpreted and identified in their

TABLE 6

Inclination of the Succedaneous Teeth

a. Disto-mesial inclination

\begin{tabular}{|c|c|c|c|c|c|c|c|c|c|c|}
\hline \multirow{2}{*}{ Name } & \multirow{2}{*}{ Sex } & \multirow{2}{*}{ Kinds } & \multicolumn{8}{|c|}{ Yrs. of observation } \\
\hline & & & 1 & 2 & 3 & 4 & 5 & 6 & & 7 \\
\hline H. S. & $\mathrm{M}$ & $\overline{\mathrm{P}_{1}}$ & - & $\mathrm{N} \quad(0)$ & $\mathrm{N} \quad(0)$ & $\mathrm{M} \frac{1}{3}\left(\frac{1}{3}\right)$ & $\mathrm{M} \frac{1}{3}(1)$ & $\mathrm{N} \quad(\mathrm{E})$ & & $\mathrm{N}$ \\
\hline S. Y. & " & $\overline{\mathrm{P}_{1}}$ & $\mathrm{~N} \quad(0)$ & $\mathrm{N} \quad(1)$ & $\mathrm{M} \frac{1}{3}(1)$ & $\mathrm{M} \frac{2}{3}(1)$ & $\mathrm{N} \quad(\mathrm{E})$ & $\mathrm{N}$ & & $\mathrm{N}$ \\
\hline N. G. & $\mathrm{F}$ & $\overline{\mathrm{P}_{1}}$ & - & $\mathrm{M} \frac{1}{3}\left(\frac{1}{3}\right)$ & $M \frac{1}{3}\left(\frac{2}{3}\right)$ & $\mathrm{N} \quad(\mathrm{E})$ & $\mathrm{N}$ & $\mathrm{N}$ & & $\mathrm{N}$ \\
\hline K. O. & "1 & $\overline{\mathrm{P}_{1}}$ & $\mathrm{M} \frac{1}{3}\left(\frac{1}{3}\right)$ & $M \frac{2}{3}\left(\frac{2}{3}\right)$ & $\mathrm{N} \quad(\mathrm{E})$ & $\mathrm{N}$ & $\mathrm{N}$ & $\mathrm{N}$ & & $\mathrm{N}$ \\
\hline A. N. & "1 & $\overline{\mathrm{P}}_{2}$ & $\mathrm{~N} \quad(0)$ & $\mathrm{N} \quad(0)$ & $\mathrm{N} \quad(0)$ & $\mathrm{M} \frac{1}{3}\left(\frac{2}{3}\right)$ & $\mathrm{M} \frac{1}{3}(\mathrm{E})$ & $\mathrm{N}$ & & $\mathrm{N}$ \\
\hline A. S. & "1 & $\overline{\mathrm{P}_{2}}$ & $\mathrm{~N} \quad(0)$ & $(0)$ & $\mathrm{N} \quad(0)$ & $\mathrm{M} \frac{1}{3}(1)$ & $\mathrm{M} \frac{1}{3}(\mathrm{E})$ & $\mathrm{N}$ & & $\mathrm{N}$ \\
\hline N. I. & "1 & $\overline{\mathrm{P}_{2}}$ & $\mathrm{~N} \quad(0)$ & $\mathrm{N} \quad(0)$ & $\mathrm{N} \frac{1}{3}$ & $\mathrm{M} \frac{1}{3}(1)$ & $\mathrm{N} \quad(\mathrm{E})$ & $\mathrm{N}$ & & $\mathrm{N}$ \\
\hline N. I. & "1 & $\widetilde{\mathrm{P}_{2}}$ & $\mathrm{~N} \quad(0)$ & $\mathrm{N} \quad(0)$ & $N \frac{1}{3}$ & $\mathrm{M} \frac{1}{3}(1)$ & $\mathrm{M} \frac{1}{3}(1)$ & $\mathrm{N} \quad(\mathrm{E})$ & & $\mathrm{N}$ \\
\hline M. A. & "1 & $\overline{\mathrm{P}_{2}}$ & $\mathrm{~N} \quad(0)$ & $\mathrm{N} \quad(0)$ & $\mathrm{N} \quad(0)$ & $\mathrm{M}^{-\frac{1}{3}}(0)$ & $\mathrm{M} \frac{2}{3}(0)$ & $\mathrm{M} \frac{2}{3}(1)$ & $\mathrm{N}$ & $(\mathrm{E})$ \\
\hline
\end{tabular}

\begin{tabular}{|c|c|c|c|c|c|c|c|c|c|}
\hline \multirow{2}{*}{ Name } & \multirow{2}{*}{ Sex } & \multirow{2}{*}{ Kinds } & \multicolumn{7}{|c|}{ Yrs. of observation } \\
\hline & & & 1 & 2 & 3 & 4 & 5 & 6 & 7 \\
\hline K. I. & $\mathrm{M}$ & $\overline{\mathrm{P}_{1}}$ & $\mathrm{~N} \quad(0)$ & $\mathrm{N} \quad(0)$ & $\mathrm{N} \quad(0)$ & $\mathrm{D} \frac{1}{3}\left(\frac{2}{3}\right)$ & $\mathrm{D} \frac{2}{3}(\mathrm{E})$ & $\mathrm{D} \frac{1}{3}$ & $\mathrm{D} \frac{1}{3}$ \\
\hline K. K. & $\prime \prime$ & $\overline{\mathrm{P}_{1}}$ & $\mathrm{~N} \quad(0)$ & $\mathrm{N} \quad(0)$ & $\mathrm{N} \quad\left(\frac{1}{3}\right)$ & $\mathrm{D} \frac{1}{3}\left(\frac{2}{3}\right)$ & $D \frac{1}{3}(E)$ & $\mathrm{N}$ & $\mathrm{N}$ \\
\hline K. M. & $\prime \prime$ & $\overline{\mathrm{P}_{1}}$ & $\mathrm{~N} \quad(0)$ & $\mathrm{N} \quad(0)$ & $\mathrm{N} \quad(0)$ & $\mathrm{N} \quad(0)$ & $\mathrm{D} \frac{1}{3}(1)$ & $\mathrm{D} \frac{2}{3}(1)$ & $\mathrm{D} \frac{1}{3}(\mathrm{E})$ \\
\hline Y. K. & $\mathrm{F}$ & $\overline{\mathrm{P}}_{2}$ & - & $\mathrm{N} \quad(0)$ & $\mathrm{N} \quad(0)$ & $N \frac{1}{3}$ & $\mathrm{D} \frac{1}{3}(1)$ & $\mathrm{D} \frac{1}{3}(1)$ & $\mathrm{N} \quad(\mathrm{E})$ \\
\hline N. S. & 11 & $\overline{\mathrm{P}_{1}}$ & $\mathrm{~N} \quad(0)$ & $\mathrm{N} \quad\left(\frac{1}{3}\right)$ & $\mathrm{N} \quad(1)$ & $\mathrm{D} \frac{1}{3}(1)$ & $\mathrm{N} \quad(\mathrm{E})$ & $\mathrm{N}$ & $\mathrm{N}$ \\
\hline Y. T. & $\prime \prime$ & $\overline{\mathrm{P}_{1}}$ & $\mathrm{~N} \quad(0)$ & $\mathrm{N} \quad(0)$ & $D \frac{1}{3}(0)$ & $D \frac{1}{3}\left(\frac{1}{3}\right)$ & $\mathrm{N} \quad(\mathrm{E})$ & $\mathrm{N}$ & $\mathrm{N}$ \\
\hline M. A. & $\prime \prime$ & $\overline{\mathrm{P}_{1}}$ & $\mathrm{~N} \quad(0)$ & $\mathrm{N} \quad(0)$ & $\mathrm{N} \quad(0)$ & $\mathrm{D} \frac{2}{3}\left(\frac{2}{3}\right)$ & $\mathrm{D} \frac{1}{3}(\mathrm{E})$ & $\mathrm{D} \frac{1}{3}$ & $\mathrm{~N}$ \\
\hline E. S. & $\prime \prime$ & $\overline{\mathrm{P}_{1}}$ & $\mathrm{~N} \quad(0)$ & $\mathrm{D} \frac{2}{3}\left(\frac{1}{3}\right)$ & D 1 (1) & $\mathrm{D} \frac{1}{3}(\mathrm{E})$ & $\mathrm{N}$ & $\mathrm{N}$ & $\mathrm{N}$ \\
\hline A. N. & $\prime \prime$ & $\overline{\mathrm{P}_{1}}$ & $\mathrm{~N} \quad(0)$ & $\mathrm{N} \quad(0)$ & $\mathrm{N} \quad(0)$ & $\mathrm{N} \quad(0)$ & $\mathrm{D} \frac{1}{3}\left(\frac{1}{3}\right)$ & $\mathrm{D} \frac{1}{3}\left(\frac{1}{3}\right)$ & $\mathrm{D} \frac{1}{3}(\mathrm{E})$ \\
\hline
\end{tabular}

(To be continued to p. 21) 
c. Those inclined both distally and mesially at eruption

\begin{tabular}{|c|c|c|c|c|c|c|c|c|c|}
\hline \multirow{2}{*}{ Name } & \multirow{2}{*}{ Sex } & \multirow{2}{*}{ Kinds } & \multicolumn{7}{|c|}{ Yrs. of observation } \\
\hline & & & 1 & 2 & 3 & 4 & 5 & 6 & 7 \\
\hline$Y . Y$. & M & $\overline{\mathrm{P}_{1}}$ & $\mathrm{~N}\left(\frac{1}{3}\right)$ & $\mathrm{M} \frac{1}{3}(1)$ & $\mathrm{N} \quad(1)$ & $\mathrm{D} \frac{1}{3}(\mathrm{E})$ & $\mathrm{D} \frac{1}{3}$ & $\mathrm{~N}$ & $\mathrm{~N}$ \\
\hline K. I . & $\prime \prime$ & $\overline{\mathrm{P}_{1}}$ & $\mathrm{~N} \quad(0)$ & $\mathrm{N} \quad\left(\frac{1}{3}\right)$ & $\mathrm{M} \frac{1}{3}(1)$ & $\mathrm{N} \quad(\mathrm{E})$ & $\mathrm{D} \frac{1}{3}$ & $\mathrm{~N}$ & $\mathrm{~N}$ \\
\hline K. K. & $\prime \prime$ & $\overline{\mathrm{P}_{1}}$ & $\mathrm{M}_{3}^{1}\left(\frac{1}{3}\right)$ & $N \quad\left(\begin{array}{l}2 \\
3\end{array}\right)$ & $\mathrm{D} \frac{1}{3}(1)$ & $D \frac{1}{3}(E)$ & $\mathrm{N}$ & $\mathrm{N}$ & $\mathrm{N}$ \\
\hline T. Y. & $\prime \prime$ & $\overline{\mathrm{P}_{1}}$ & $\mathrm{~N} \quad(0)$ & $\mathrm{N} \quad(0)$ & $\mathrm{M} \frac{1}{3}(1)$ & $\mathrm{N} \quad$ (1) & $\mathrm{D} \frac{1}{3}(\mathrm{E})$ & $\mathrm{N}$ & $\mathrm{N}$ \\
\hline K. T. & $\prime \prime$ & $\overline{\mathrm{P}_{1}}$ & 一 & $\mathrm{N} \quad\left(\frac{1}{3}\right)$ & $M \frac{1}{3} \cdot(1)$ & $\mathrm{D} \frac{1}{3}(\mathrm{E})$ & $\mathrm{N}$ & $\mathrm{N}$ & $\mathrm{N}$ \\
\hline S. Y. & $\prime \prime$ & $\overline{\mathrm{P}_{1}^{\prime}}$ & - & $\mathrm{M}^{\frac{1}{3}}(1)$ & $D \frac{1}{3}$ & $\mathrm{D} \frac{1}{3}$ & D $\frac{1}{3}$ & $\mathrm{~N}$ & $\mathrm{~N}$ \\
\hline
\end{tabular}

Note: Indication of figures ( ), E. same as Table 5 .

trabecular patterns. 20 boys and 24 girls for the lower anterior region and 22 boys and 26 girls for the lower molar ragion were thus selected.

The identification and classification of trabecular patterns were conducted according to Braunschweiger's method[6], i. e., the spreading of trabeculae runs in parallel to the tooth axis, right angle, oblique angle and combination of the two or reticular pattern. 3.6.1 Radiograms are, generally speaking, the images based on simultaneous patterning of a spot under the routine radiography and, for this reason, it is very difficult to observe a specific thin spot radiographically.

In radiographing the mandibular alveolar bones, complex situations are encountered in terms of fusing together of bone trabeculae and positional relationship on the right and left sides on account of difference in labio-lingual or bucco-lingual thicknesses of the bone involved. Even admitting this difficulty, still the labio-lingual or bucco-lingual thicknesses of the alveolar bone of the mandible are smaller as compared with that of the maxilla anatomically and, therefore, radiographic patterns of the trabeculae in these regions lend themselves to a fairly accurate interpretation. Of 281 radiograms used in the present study, however, only $44(15.7 \%)$ were capable of interpretation in the anterior while $48(17.1 \%)$ were interpretable in the molar regions (Table 7 ).

3.6.2 On 281 radiograms the authors could not discover the parallel pattern by Braunschweiger and therefore, we used fourfold classification of rectangular, oblique, mixed and reticular. This classification, however, is based on a mere subjective judgment and

TABLE 7

Classification of Cancellous Patterns in the Interpretable Cases (44 anterior regs., 48 posterior regs./281 subjects)

\begin{tabular}{|c|c|c|c|c|c|c|}
\hline Regions & \multicolumn{3}{|c|}{ Molar: $\overline{\mathrm{P}_{1}}, \overline{\mathrm{P}_{2}}$} & \multicolumn{3}{|c|}{ Anterior: $\overline{\mathrm{I}_{1}}, \overline{\mathrm{I}_{2}}$} \\
\hline $\begin{array}{ll} & \text { Sex } \\
\end{array}$ & M & $\mathrm{F}$ & Total & M & $\mathrm{F}$ & Total \\
\hline Rectangular & 8 & 6 & 14 & 9 & 13 & 22 \\
\hline Mixed & 14 & 20 & 34 & 11 & 11 & 22 \\
\hline
\end{tabular}


Fig. 7. Forming pattern of the alveolar crest in inclinating eruption $\left(\overline{\mathrm{m}_{1}}\right.$ and $\overline{\mathrm{P}_{1}} ; \overline{\mathrm{m}_{2}}$ and $\overline{\mathrm{P}_{2}}$ ) (I. I., Male)

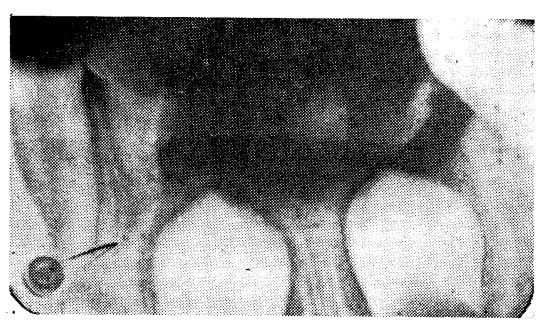

$7.2(86)$

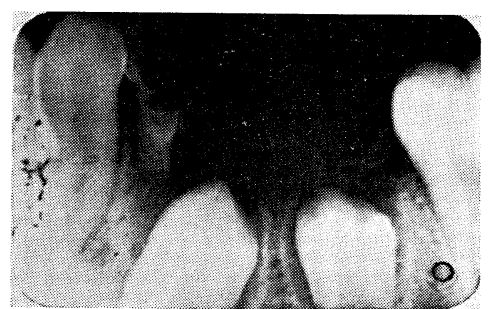

$8.2(98)$

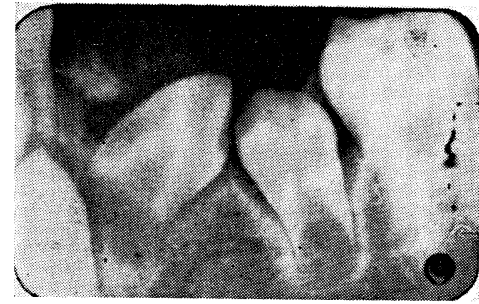

$9.2(110)$

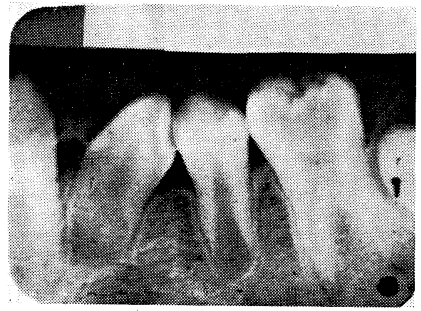

$10.2(122)$

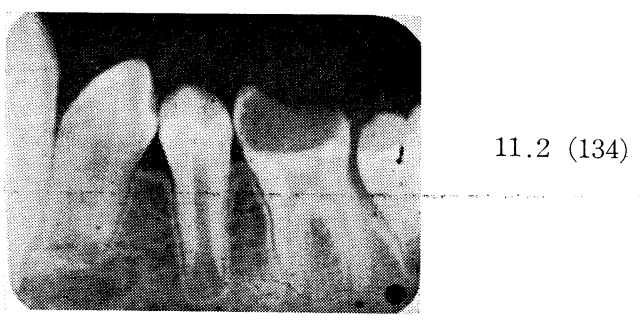


Fig. 8. Classification of cancellous patterns (Schematic presentation)

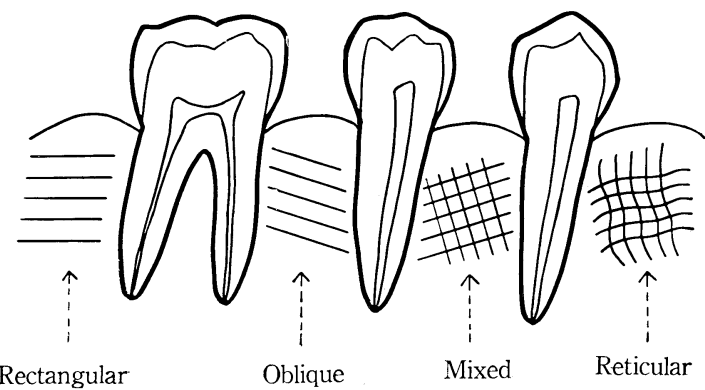

Fig. 9. Radiograms of cancellous patterns

Rectangular pattern

$\overline{2.1 \mid 1.2}$

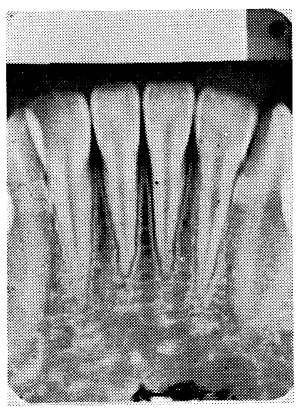

$\overline{2.1 \mid 1.2}$

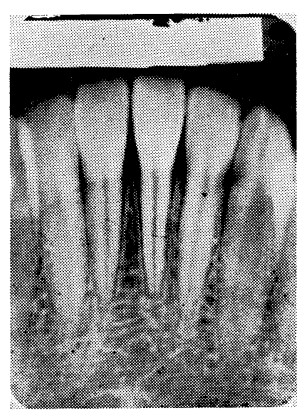

$\overline{5.4}$

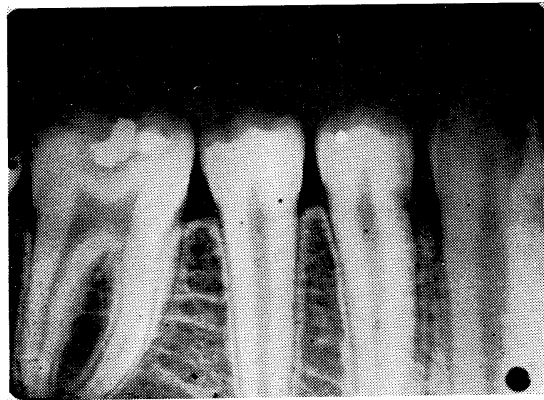

Mixed pattern

$\overline{5 .} \cdot \overline{4}$

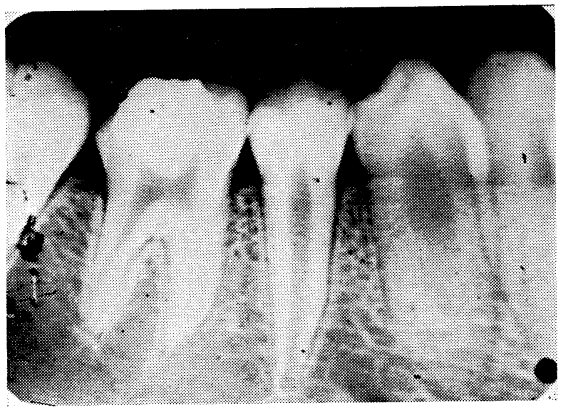


it would be more objectively true if the first two types are combined as rectangular and the last two as mixed patterns. Of the radiograms which could be interpreted of their trabecular patterns, there were $22(50.0 \%)$ rectangular and $22(50.0 \%)$ mixed patterns out of 44 as regards the anterior region, while there were $14(29.2 \%)$ rectangular and $34(70.8 \%)$ mixed patterns out of 48 as regards the molar region (Table 7 , Figs. 8, 9).

\section{Summarization and Considerations}

In the present investigations, the authors placed their emphasis on the lower premolar region which lent itself most easily to the standardized radiography and they further investigated the lower anteriors.

For the purpose of accuracy, they had devised an isometric technic for intraoral radiographic method and by means of this technic, reliable chronological investigations over number of years were possible.

4.1 When there is found no periapical rarefaction of the precursor to speak of, the physiologic resorption of its root goes on in direct contact with the successor and, at the same time, bone maintenance of the precursor is lost and its shedding will take place. On this occasion, bone crypt of the successor will transfer into the crest of the intraalveolar septum that is newly produced. But the period when the normal lamina dura corresponding to the root surface is formed, is usually the time at which contact point is established with the approximal teeth and the occlusal function is participated in. The interval required for the transfer is given to be from 6 months to 2 years, varying widely from individual to individual.

4.2 When there exists some kind of periapical rarefaction of the deciduous root, eruption of succedaneous teeth will take place in proportion to the degree of deciduous root resorption. However, it is when pathologic split of the precursor root occurs that formtion of the alveolar bone in that spot will be checked or interferred with. Formation of the normal lamina dura around the successor is usually associated with the establishment of a contact point with approximal teeth and participation in the occlusal function. It takes anywhere from 2 to 3 years for this to take place, differing widely from individual to individual, and some of them are excessive prematurely.

4.3 Premature loss of the precursors varies greatly in terms of pathologic resorption of the alveolar bone in question. That is to say, when the entire bone crypt over the succedaneous tooth has been pathologically resorbed, the successor will erupt having no connection with the calcification degree of its root, and the remaining part of that bone crypt will transfer itself toward the alveolar crest of the successors. In these instances, however, permanent teeth may sometimes tend to erupt without forming the periodontal space at all.

On the contrary, when a precursor has been lost on account of a partial rarefaction of the alveolar bone in the periapical region, defective portion in the bone crypt will be osseously repaired and a successor will remain inside the bone. In this instance, the successor in question will erupt by breaking through the bone crypt when the calcification of its root has advanced after some passage of time to attain to the root formation by nearly $1 / 2$. And then the residue of the bone crypt will be transferred as it is into the alveolar crest of the successor to form its lamina dura. These transforming are observable extending from 4 to 5 years. 
4.4 Similar appearances which are observed in the lower anterior region are basically the same as those that occur in the lower molar region.

4.5 A successor which has been rotated inside the bone will erupt in that state, as long as it comes under no influence by the approximal teeth. On the other hand, when some influence is exerted by the neighboring teeth, the bone structure under influence will decrease and its peculiar bone trateculation may ke sometimes lost.

When influence by the approximal teeth ceases by one cause or another, the rotation of a tooth axis involved will return to the normal direction and, in association with this, the bone structure around the rotating teeth will be also restored to normality.

4.6 The authors were able to classify the trabecular patterns of cancellous sponginosa in the alveolar bone into 4 types: rectangular, oblique, mixed and reticular. This classification, however, is based on a mere subjective judgment and as it is not always easy to distinguish one from other types, it might be better to be more objectively if the first two types are combined as rectangular and the latter two as mixed broadly.

As regards the rotation of a tooth in the bone, FujiTA [7] has the following to say: "The rotation of a tooth may be broadly mentioned as one of the abnormalities of tooth position. Though difficult to assign definite causes to the rotation, one cause is that confusion is brought about in dental arch by the contraction of jawbone and another cause may be that the rotation is secondarily induced by some kind of malocclusion or loss of the approximal teeth around a tooth that has normally erupted".

The rotated teeth under examination by the authors were not of this type, but were those in which effect of the approximal teeth must have been exerted on the threshold of eruption in that the succedaneous teeth were still in the alveolar bone and their crowns were just beginning to become calcified. Moreover, as far as the result of their investigations were concerned, the authors have found that contact relation with the approximal teeth had beneficial effects on rectifying the rotated axes of teeth at fault into the correct position in many cases. Such investigators as BRAUNSCHWEIGER [6], OYASHIKI [8], MASUdA [9] and OTAKE[10] have given their radiological considerations of the structure of the alveolar bone trabeculation. These reports seem to give too detailed classifications of the trabecular patterns seen in individuals.

With the roentgenograms of 1500 clinic patients at the University of Alabama School of Dentistry, PARFITT[11] classified their alveolar trabecular patterns into 3 classes: coarse, medium and fine with respective percentage distributions. Based on his findings, PARFITT gave his conclusion that "The incidence of coarse trabeculation tends to decrease up to the age of 10 , after which it increases with advancing age. The incidence of fine trabeculation increases slightly throughout life. In spite of this trend, the ratio of coarse, medium and fine trabeculation remain similar, regardless of age, and there is no difference in this respect between the sexes and races".

\section{Conclusions}

5.1 Even in the case where a deciduous tooth is replaced by its successor through the physiological root resorption or where a pathologic split of the deciduous tooth remains, the bone crypt of a successor will transfer itself as it is into the new crest of interalveolar septum when that deciduous tooth involved is lost.

5.2 By the time when eruption of the permanent teeth has advanced to such a stage where the occlusal function becomes possible with the approximal teeth, formation of the 
alveolar bone structure will have been nearly completed. However, when a split of the deciduous root is involved, the speed of bone-crest formation will be much delayed.

5.3 When a precursor happens to ke prematurely lost, its successor will either erupt much earlier or not erupt until the average stadium of successional replacement, depending upon the degree of destruction on the part of the bone crypt.

5.4 With the permanent teeth which have insufficient root formation but participate in the occlusion at an early period, the authors may observe much quicker formation of the alveolar bone.

5.5 The period from the loss of precursors to the routine replacement of successors is anywhere from 1 to 2 years under the normal conditions. Under the abnormal conditions, however, this period extends by 2 to 3 years, and some of them are excessive prematurely.

5.6 Twisting or inclination of the permanent teeth in the jaws have no particular relation to the structure of their adjacent bone. But effects of the precursors or conditions of the approximal teeth cannot be ignored at the time of succedaneous dentition.

5.7 Appearance of the alveolar bone in the lower anterior region at successional replacement is basically the same as that regards the lower molar region.

5.8 Fourfold classification of cancellous pattern of spongiosa seen in the alveolar bone trabeculation attempted by other workers seems to be too subjective. In the opinion of the present authors, twofold classification of them into rectangular and mixed types will be more reasonable immediately after the successional replacement.

The ratio of rectangular and mixed types calculated by the authors was $1: 1$ in the anterior region, while it was $1: 2.5$ in the molar region.

\section{References}

[1] Akryoshi, M. : An investigation of the patho-histology in periodontal tissues - An addendum of the productive process of secondary dentin and bundle bone, J. Japan stomatol. Soc., Vol. 16, pp. 487-488 1942.

[2] Ditto: Structure and Pathology of the Parodontium, 1st ed., Ishiyaku Publ. Co., Tokyo, p. 53-65, 83-88 1963.

[3] FujitA, K. : Histology of the Teeth, 5th ed., Ishiyaku Publ. Co., Tokyo, pp. 171-179 1963.

[4] Aizawa, K., Sanka, Y., Nakashima, T. and Shinbo, K. : A new roentgenographic isometric technic for intraoral method, Dental radiology, Vol. 3, pp. 18-23 1962.

[5] Ando, S. : Dental Radiology, 2nd. ed., Ishiyaku Publ., Tokyo, pp. 151, 183-196 1964.

[6] Braunschweiger, H. : Die Bedeutung der Spongiosa des Unterkiefers für das Röntgenbild, Dtsch. Zahnhlk, Vol. 56, S. 64-74 1922.

[7] Fujita, K. : Anatomy of the Teeth, 9th ed., Kanehara Publ. Co., Tokyo, pp. 137-138 1964.

[8] OyAshrki, M. : A study on the alveolar trabeculae, J. Radiol. \& Physic. Therapy, Univ. of Kanazawa, Vol. 64, pp. 105-149 1961.

[9] Masuda, T. : Morphological study of the mandibular canal, J. Japan Dent. Asso., 7th supplement, p. 1171958.

[10] OTAKe, M. : A roentgeno-anatomical investigation of the mandibular bone, Nippon Acta Radiologica, Vol. 11, p. 91951.

[11] PARfitT, G. J. : An investigation of the normal variations in alveolar bone trabeculations, O. s., O. m., \& O. p., Vol. 15, pp. 1453-1463 1962. 